\title{
Morphological Characteristics of the Mucous Membrane of the Ileum and Colon before and after Surgical Correction of the Insolvency of the Bauhinia Valve
}

\author{
Martynov Vladimir Leonidovich* and Kazarina Natalia Vladimirovna \\ Department of Surgical, Russia
}

*Corresponding author: Martynov Vladimir Leonidovich, Department of Surgical, City Clinical Hospital №12 Sormovo district of

Nizhny Novgorod, Russia

\begin{tabular}{ll}
\hline ARTICLE INFO & ABSTRACT \\
\cline { 1 - 1 } $\begin{array}{l}\text { Received: } \\
\text { Published: May 05, } 2019\end{array} \quad \begin{array}{l}\text { Citation: Martynov Vladimir L, Kazarina Natalia V. Morphological Characteristics of the Mu- } \\
\text { cous Membrane of the Ileum and Colon before and after Surgical Correction of the Insolven- } \\
\text { cy of the Bauhinia Valve. Biomed J Sci \& Tech Res 18(1)-2019. BJSTR. MS.ID.003105. }\end{array}$ \\
\hline
\end{tabular}

\section{Opinion}

Introduction Currently, there is a paradoxical situation where the dominant medical opinion recognizes the harmfulness of dysfunction of such barrier structures as cardia, gatekeeper, Oddi's sphincter, heart valves, lower extremity vein valves, etc., but ignores the failure of the ileocecal locking apparatus (Bauhinia valve ) as a possible cause of the pathology of the digestive system, as well as various extraintestinal diseases [1]. But also I.I. Grekov expressed the position [2]. Which retained its relevance: "Despite a number of works devoted to the proximal part of the large intestines, the pathology of this department is still not sufficiently explained because in these works the role of the Bauhinium valve was completely ignored". We assign one of the leading roles in the digestive system to the ileocecal locking apparatus, which delimits the functions of the small and large intestines, isolating the small intestine from the reflux of the colonic contents, which differs sharply in chemical composition, physical condition and bacterial spectrum [3-5]. So, according to L.G. Peretz (1955), in $1 \mathrm{ml}$ of intestinal contents there are up to 5000 microbes, and in $1 \mathrm{~g}$ of the contents of the large intestine there are about 30-40 billion [6].

As a result of NBZ, billions of colon microbes are thrown into the small one $[4,6]$, the colon is colonized with allochthonous (alien) microorganisms, an overgrowth syndrome (SIBR) or enteric dysbacteriosis develops $[7,8]$. The waste products of microorganisms (indole, phenol, cresol, skatole, pyrocatechin, carbolic acid, hydrogen sulfide, mercaptan, ethane, methane, etc.) being absorbed into the blood, cause autointoxication phenomena. These metabolites cannot be sufficiently detoxified, especially in liver diseases [7,9-11]. SIBO leads to the development of putrefactive and fermentation processes in the small intestine. At the same time, the barrier role of the intestinal wall is violated $[4,12]$, lymphoid tissue suffers along the gastrointestinal tract, and the result is a deficiency of immunoglobulins $\mathrm{A}$ and $\mathrm{M}$. The body becomes less protected before microbial aggression. It was found that in $82.4 \%$ of patients with chronic colitis, in $70 \%$ of patients with chronic enterocolitis, a marked decrease in the immunological reactivity of the organism is observed [5].

All authors recognize the NBZ as one of the anatomical causes of SIBO, but do not have a therapeutic effect on it $[13,14]$. Currently, SIBO is recognized as a key pathogenetic mechanism in many diseases of the digestive tract and associated extra-digestive conditions [7,10]. I Cohn (1970) emphasizes that the ileocecal valve and the ileum control the flora of the small intestine. The presence of fecal microflora in the small intestine per se during the development of NBZ is harmful, even if it does not cause clinical pathology in some patients [27,142,122,344]. M Brotman [15] found that about $95 \%$ of bile acids that re-enter the liver are normally absorbed in the ileum, GG Nemsadze \& EP Rybin [16,17] identified in a group of 192 cancer patients large intestine a significant increase in the excretion of bile acids with insolvency Bauhinia valve, compared with its normal function. Indirect data on the possible role of NBZ 
in increasing the excretion of bile acids were obtained by analyzing the characteristics of bile acid metabolism in the enterohepatic cycle [18-20]. Some authors suggest that, through the formation of carcinogenic substances from bile acids, bacteroids may contribute to an increased incidence of colon cancer [21] and colon cancer". One of the objectives of the study was the morphological confirmation of the clinical effectiveness of bauginoplasty demonstrated above. The biopsy specimens of the mucous membrane of the ileum and large intestines were analyzed.

\section{Morphological Study of Drugs}

During endoscopic examination (rectoromanoscopy, fibrocolonoscopy), a biopsy specimen was taken from the mucous membranes of the rectum and colon. Studies were performed before the operation and one year after it during the control examination. The morphometric assessment of the biopsy was performed using the Avtandilova GG mesh. with the inclusion of the program "Excel". Morphological analysis was performed by examining a series of paraffin sections of 5-7 micrometers thick, stained with hematoxylin and eosin using morphometry. Tissue resistance of the esophageal mucosa was assessed by the presence or absence of loosening of the epithelium, the length of the subepithelial papillae, vascularization of the epithelial layer and the state of its own plate. An automatic computerized image processing system based on a Nicon E-400 microscope was used. The study of biopsy specimens of the mucous colon at NBZ allowed us to establish various degrees of inflammation with infiltration of lymphoid cells (96\%), histiocytes $(46 \%)$ and plasma cells (28\%). Phenomena of edema occurred in $92 \%$ of studies, fibrosis - in $65 \%$.

In addition, hemorrhages (20\%), as well as the proliferation of intestinal epithelium (27\%) were detected. The normal structure of the mucous membrane of the colon is observed only in $12 \%$ of cases. Histological examination of the colon mucosa in 24 patients before the operation, as well as a year or more later, a decrease in the inflammatory process was detected (biopsy specimens were taken during fibro colonoscopy and rectoromanoscopy). Sclerosis and fibrosis of the submucosal layer was recorded in 9 patients, before the operation it occurred in 16 patients $(p=0.041)$. The proliferation of the epithelium of the mucous membrane of the colon after the operation occurred in 7 , while before the operation in 6 examined ( $p=0.5$ ). Infiltration with plasma cells was observed in 1 patient, whereas before the operation it was observed in 6 (p $=0.049$ ). Edema was found in 2 patients, and before the operation it was observed in 22 ( $\mathrm{p}<0.001)$. Infiltration with lymphoid cells was detected in 8 patients, and before the operation, it was observed in 23 patients $(\mathrm{p}<0.001)$. The normal structure of the mucous membrane was detected in 13 patients, whereas before the operation only in 3 patients ( $p=0.025$ ). Morphometric indicators of the mucous membrane also confirm the reduction of inflammation, the normalization of cell characteristics, which prepares a structural basis for the normalization of their function.
A comparative morphometric analysis showed that in patients with NBZ in the long-term period after the operation, a decrease in the cell density of the infiltrate in the own mucosal plate occurs ( $p<0.001)$. In spite of the fact that lympho-plasmocytic infiltration was preserved in its own plate, its severity was regarded as weak or moderate. The distinct decrease in eosinophilic infiltration ( $p<0.001)$ and neutrophilic $(p<0.001)$ granulocytes observed in parallel with this indicates an improvement in the microcirculation system in the duodenal mucosa, which helps to restore the metabolic functions of the muscle plate. Thus, in the conditions of the NBZ, chronic inflammation is formed in the mucous membrane of the colon, for the elimination of which the most adequate method is Bauginoplasty. NBZ is accompanied by a pronounced picture of chronic inflammation of the colon, which reduces the function of the organ and dangerously develops the tumor process. Adequate correction of NBZ, as the cause of SIBO in the small intestine, in the form of Bauginoplasty, provides for the arrest and regression of the chronic inflammatory process, being the prevention of colon cancer.

\section{References}

1. Martynov VL (2006) Refluxes of the digestive tract and their surgical correction: author. diss Martinov Vladimir Leonidovich Saransk pp. 261.

2. Grekov II (1927) Bauhinini spasm and bauginoplasty (on the issue of socalled chronic appendicitis, recurrence of pain after appendectomy and their treatment). Herald of Surgery № 9: 122-151.

3. Larry S Miller (2012) Ileocecal valve dysfunction in small intestinal bacterial overgrowth: A pilot study. WGJ V 18(46): 6801-6808.

4. Vitebsky Ya D (1973) Essays on surgery of the ileocecal region of the intestine. Medicine pp. 111.

5. Nogaller AM (1945) Allergy and chronic diseases of the digestive system (diagnosis and treatment of food, microbial and tissue allergies). M Medicine pp. 227.

6. Peretz LG (1955) The value of normal microflora for the human body Medgiz pp. 436

7. Kurygin AA (1993) Clinical aspects of the syndrome of excessive colonization of the small intestine by the colonic microflora. Herald of Surgery № 150(4-6): 118 - 123.

8. Gibert BK (1984) Experimental substantiation and surgical treatment of reflux ileitis in case of acquired insufficiency of the ileocecal locking apparatus: author. dis kand honey. Sciences Perm p. 42.

9. Dubyag AN, BK Gibert (1980) On the diagnosis and treatment of refluxileitis Herald of Surgery. 1: 49-53.

10. Konev YuV (1999) Endotoxin and aging. Klin gerontol 4: 43-52.

11. Smirnova TV (1987) Indirect method for the detection of intestinal dysbiosis. Medical business. - № 6: 90-921.

12. Askarov AA, AA Finkel (1959) Terminal ileitis in case of insufficiency of the bauhinia valve in patients with chronic colitis. Izv AN Uz SSR Ser the medicine 6: 49-54.

13. Plotnikova E Yu (2013) Some aspects of diagnosis and treatment of excessive bacterial contamination of the small intestine in clinical practice p. 4.

14. Gabrielli M (2013) Diagnosis of small intestinal bacterial overgrowth in the clinical practice. European Review for Medical and Pharmacological Sciences 17: 30-35 
15. Brotman M (1976) Inflammatory bowel disease, treatable physiological disorders that occur after surgical treatment. Dis Colon Rectum 19(7) 588-590.

16. Nemsadze GG, MA Akopov, DZ Deradashvili (1988) New in the diagnosis of colon cancer, Sabchata medicine 3: 48-51.

17. Nemsadze GG, BA Dolidze, EP (1960) Rybin Features of excretion of bile acids in patients with colon cancer. Questions of Oncology 36(5): 549552.

18. Bocharova LV (1985) The metabolism of bile acids. Sov Med 5: 84-87.

19. Haenel H, I Bending (1975) Intestinal flora in health and disease. Progr Food a Nutr 21: 1-86.

\section{ISSN: 2574-1241}

DOI: 10.26717/BJSTR.2019.18.003105

Martynov Vladimir L. Biomed J Sci \& Tech Res

(C) $(9)$ This work is licensed under Creative

Submission Link: https://biomedres.us/submit-manuscript.php
20. Reddy BS, Wynder EL (1977) Metabolic epidemiology of colon cancer. Fecal bile acids and neutral sterols in colon cancer patients and patients with adenomatous polyps. Cancer 39(6): 2533- 2539.

21. Wynder EL (1975) The epidemiology of large cancer. Cancer Res 35: $3388-3394$.

22. Nemsadze GG (1990) The functional state of the ileocecal apparatus in patients with colon. Bulletin of Surgery 144(4): 21-23.

$\begin{array}{ll}\text { BIOMEDICAL } & \text { Assets of Publishing with us } \\ \text { RESEARCHES } & \text { - Global archiving of articles } \\ & \text { - Immediate, unrestricted online access } \\ & \text { - }\end{array}$

